\title{
EFFECT OF Fillet RADIUS ON ALUMINIUM Silicon CARbide METAL MATRix CoMposite SPUR GEAR
}

\author{
Atul Sharma ${ }^{1}$, M.L. Aggarwal ${ }^{2}$ and Lakhwinder Singh ${ }^{3}$ \\ ${ }^{1,2,3}$ Department of Mechanical Engineering, YMCA University, Faridabad, India
}

\begin{abstract}
Aluminium silicon carbide metal matrix composite spur gear has low density, good strength to weight ratio, excellent castability and corrosion resistance. During working, the root of the spur gear teeth is subjected to stress concentration and crack initiation starts leading to failure of material. In the present work, the effect of varying fillet radius on stress and strain at the root of spur gear is estimated. FEA analysis is used for building the model for predicting the design parameters at varying fillet radii. This paper demonstrates the effect of the fillet radius on design parameters of metal matrix composite made up of Aluminium and Silicon Carbide to enhance its strength.
\end{abstract}

\section{KEYWORDS}

Tooth Fillet, MMC, FEA, Spur Gear, Ansys, Design Parameters, Failure.

\section{INTRODUCTION}

Particulate composites consist of discrete particles of one material surrounded by a matrix of another material. The reinforced material is silicon carbide and the matrix material is aluminium in the present analysis. The composite material particles maintain their identities even after a composite material is fully formed. The metal matrix composite material possesses good strength to weight ratio, excellent castability, corrosion resistance and is light in weight.

Gears are used in mechanical power transmission systems in a wide variety of applications. Gears are now highly specialized to tooth shape and size. The designer is always faced with the problem of stress concentration, at sections having abrupt change of shape; root of the gear tooth is the area where stress concentration occurs; the best that can be done is to minimize its effects. The general guideline, for designing of minimum stress concentration, is to avoid sharp corners completely and to provide largest possible transition radius between surfaces of different contours. Checking the gear for strength is a difficult task than to check run out, profile, lead, pitch variation and misalignment. Fillet radius dimensions are rarely defined on the drawing; geometric and dimensional constraints are insufficient to define the root fillet radius of gears.

In this paper, $\mathrm{Al}-\mathrm{SiC}$ metal matrix composite(10\% $\mathrm{SiC}$ particle) has been taken as a gear material and then developed a finite element analysis model. This is followed by the investigation on the effect of tooth fillet radius variation on stress, strain, deflection and factor of safety. As composite material have gained priority among material with the integral property 
of light weight and strength, aluminium silicon carbide metal matrix composite is the best option in case of gears, where there is the requirement of weight reduction, strength enhancement, corrosion resistance and better life of component.

Spur gear is characterised by tooth breakage due to bending and surface failure; out of this, tooth strength in bending is critical; tooth absence disables the gearbox, but pitting of the surface gives sufficient time for its replacement. During working, maximum stress is generates at the root; as it's the end of tooth which acts as the cantilever.

Undercutting is the phenomenon which occurs when dedendum is large enough to extend below the base circle resulting in profile which is not an involute at the fillet radius. This can be avoided by limiting the minimum number of teeth to 17 for the pinion with 20 degree pressure angle. The fillet radius which is generated automatically due to the cutting motion of cutter is known as trochoidal fillet. Its value is defined as 0.3 times module for coarse pitch gear and for fine pitch gear its value is not defined.

Through a lot of work has done on fillet radius of spur gear but its value for fine pitch gear value is not defined so far. Here a finite element analysis model has been developed, in which by putting the different value of tooth fillet radius: the Von- Mises stress, strain, deformation can be obtained from ANSYS work bench through finite element analysis and factor of safety for spur gear can be calculated.

\section{LITERATURE SURVEY}

In recent years, fillet radius has gained huge importance in the field of spur gear application because of its contribution in strength and thus researchers around the globe have shown interest in studying it. A. Kapelevich et.al., (2009) worked on the fine pitch gears for calculating the stresses at different tooth fillet radius by fixing the number of teeth to 24 and diametral pitch equal to 12 and found enhancement of bending strength. Christos A. Spitas et.al., (2006) replaced standard trochoidal fillet teeth with circular fillet teeth for stress analysis of teeth numbers varying from 9 to 40 but it should be generalised. Prabhu Sekar et.al., (2014) selected higher speed ratio and profile shifted gear drives for fillet stress calculation. Shanmugasundaram Sankar et.al., (2010) concentrated on the gear with number of teeth less than 17 and studied the effect of fillet radius on it but this method does not show its benfits on big gears. N.L. Pedersen (2014) studied the involute shape and changes the fillet radius,the improvement in stress level is 31 to $8 \%$. In these studies the lesser the number of teeth higher will be the improvement in stress values.

Ognyan Alipiev et.al., (2013) studied the fillet radius of rack cutters and non-traditional undercutting and found the maximum value of fillet radius for which ther is no undercutting. Th. costopoulos et.al., (2009) studied the effect of fillet radius on stresse of one sided involute asymmetric teeth for special cases but in day to day working, rotation in both the direction is required.In this model the reduction of stress upto 28\% is measured. Ashwini joshi et.al., (2011) worked on fillet radius for gear with 14 and 30 number of teeth and found the reduction in deflection and stress values. J.L. Woods et.al., (1999) incorporated the fillet radius with presetting of teeth and proved analytically and experimentally the increment of bending strength and load carrying capacity increased by $43 \%$. In these studies fillet radius effects on cutting tools, asymmetric teeth, number of teeth,presetting are focused and found stress reduction. 
Mir Ali Ghaffari et.al., (2015) used a boron epoxy patch on different fillet radius teeth and found that the bending strength of the teeth increase for the load cycles of 60000 . Tengjiao Lin et.al., (2006) worked on mesh generation of tooth root fillet model for calculating the static and dynamic loading. Harold van malick (2007) compared the steel and plastic gear for their load carrying capacity for changing root fillets. In this root fillet of $0.3 \mathrm{~mm}$ instead of $0.1 \mathrm{~mm}$ reduces the stress value by $30 \%$. Nizar Ahamed et.al., (2014) worked on the propagation of crack in tooth fillet for different values.The study is about different values ranging from $10 \%$ to $50 \%$ fillet crack. Yogesh Pandya et.al., (2013) worked on the crack path for different fillet radius and used a straight crack propagaton for the higher values. In these studies the tooth fillet radius is analysed by incorporating patches, fine mesh generation, materials, radius values, crack path and its effect is found out.

Bernd Robert Hohn et.al., (2011) worked on fillet radius ranging from 0.3 to $1 \mathrm{~mm}$ and found out that for small size gear the load capacity related to torque increases upto 1.5 times, for steel 17CrNiMo6 but these should be for all type of gears. S.Senthilvelon et.al., (2006) found out that gear tooth fillet radius affects the polymer gear performance in terms of life,crack, deflection and heat generation. In this paper it was found that fatigue life of $0.75 \mathrm{~mm}$ fillet gear is more than $0.25 \mathrm{~mm}$ fillet. V. Senthil Kumar et.al., developed non standard rack cutter of different fillet radius and found out that stress values reduced from 30.18 to $29.98 \mathrm{MPa}$. In these studies small size gear, plastic material, steel and non standard design incorporated with fillet variations and increment in strength is noticed.

From the literature review, it is evident that researchers have extensively studied the root fillet radius of gears and have shown that root fillet improves the properties of gears. However, little work is available that deals with the method of finding optimum tooth fillet radius for Aluminium Silicon Carbide metal matrix composite material fine pitch spur gear using CAD analysis. Thus in the present study, finite element analysis model has been developed to find out the fillet radius for fine pitch gear. The load is applied on teeth for varying fillet radius and comparisons are done for the Von-Mises stress, strain, deformation and factor of safety.

\section{MeTHODOLOGY}

The proposed model is constructed by taking the module, number of teeth and face width as fundamental specification followed by calculating the detailed dimensions which include addendum, dedendum, pressure angle, tooth thickness , pitch circle diameter, outer diameter, root diameter, base circle diameter, circular pitch as given in table 1 .

After making the two dimensional drawing, in Pro-E $\rightarrow$ exit workbench $\rightarrow$ go to solid modelling; give the pad command for creating the solid model; this model is imported to ANSYS workbench by file $\rightarrow$ import $\rightarrow$ IGES. 
Table 1 :- Specification of spur gear with 17 teeth

\begin{tabular}{|c|c|c|c|c|}
\hline S.No. & Description & Symbol & Description & $\begin{array}{c}\text { Value( } \\
\mathrm{mm})\end{array}$ \\
\hline 1 & Number of teeth & $\mathrm{z}$ & Required value & 17 \\
\hline 2 & Module & $\mathrm{m}$ & Required value & 1.25 \\
\hline 3 & Addendum & $\mathrm{h}_{\mathrm{a}}$ & $\mathrm{h}_{\mathrm{a}}=1 \mathrm{~m}$ & 1.25 \\
\hline 4 & Dedendum & $\mathrm{h}_{\mathrm{f}}$ & $\mathrm{h}_{\mathrm{f}}=1.25 \mathrm{~m}$ & 1.562 \\
\hline 5 & Pressure angle & $\alpha$ & degree & 20 \\
\hline 6 & Tooth thickness & $\mathrm{t}$ & $\mathrm{t}=1.6 \mathrm{~m}$ & 1.96 \\
\hline 7 & Tooth height & $\mathrm{h}$ & $\mathrm{h}=\mathrm{h}_{\mathrm{a}}+\mathrm{h}_{\mathrm{f}}$ & 2.812 \\
\hline 8 & Face width & $\mathrm{w}$ & Required value & 10 \\
\hline 9 & Pitch circle diameter & $\mathrm{d}$ & $\mathrm{d}=\mathrm{mz}$ & 21.25 \\
\hline 10 & Root diameter & $\mathrm{d}_{\mathrm{f}}$ & $\mathrm{d}_{\mathrm{f}}=\mathrm{d}-2 \mathrm{~h}_{\mathrm{f}}$ & 18.12 \\
\hline 11 & Outside diameter & $\mathrm{d}_{\mathrm{a}}$ & $\mathrm{d}_{\mathrm{a}}=\mathrm{d}+2 \mathrm{~h}_{\mathrm{a}}$ & 23.75 \\
\hline 12 & Base circle diameter & $\mathrm{d}_{\mathrm{b}}$ & $\mathrm{d}_{\mathrm{b}}=\mathrm{d} \cos \alpha$ & 19.96 \\
\hline
\end{tabular}

\subsection{Finite Element Analysis}

In the finite element analysis, a systematic process is followed for reaching final values of design parameters. It includes dividing the spur gear into small elements and effect of load is studied on one tiny element. Following steps are covered for analysis.

Step 1:- Element definition.

Go to Ansys main menu $\rightarrow$ Element type $\rightarrow$ add/edit/Delete, select $\rightarrow$ element type ,typ1 SOLID $187 \rightarrow$ add $\rightarrow$ ELIST Command. After giving the element definition the model get divided into this equispaced finite element.

Step 2:- Material properties.

Go to mechanical utility menu $\rightarrow$ pre-processor $\rightarrow$ material properties $\rightarrow$ Define material model behaviour $\rightarrow$ material modes available $\rightarrow$ structural $\rightarrow$ linear $\rightarrow$ Elastic $\rightarrow$ Isotropic $\rightarrow$ Linear Isotropic material properties for material number 1,put value of Poisson's ratio 0.3 , density $2.88 \mathrm{gm} / \mathrm{cc}$, Youngs modulus $1.15 \mathrm{E}+05$, tensile yield strength $487 \mathrm{MPa}$,Tensile ultimate strength $690 \mathrm{MPa}$ as shown Table 2 .

Table 2 :- Material properties of $\mathrm{Al}-\mathrm{SiC}$

\begin{tabular}{|l|l|}
\hline Description & Values \\
\hline Density & $2.88 \mathrm{~g} / \mathrm{cc}$ \\
\hline Ultimate tensile strength & $690 \mathrm{MPa}$ \\
\hline Yield tensile strength & $487 \mathrm{MPa}$ \\
\hline Poisson's ratio & 0.3 \\
\hline
\end{tabular}


Step 3:- Meshing the spur gear.

Define the meshing properties by going to ANSYS main menu $\rightarrow$ the meshing $\rightarrow$ the mesh tools and put the element edge length of $1 \mathrm{~mm}$ in element sizes on picked lines $\rightarrow$ yes in KYNDIV SIZE, NDIV can be changed option. Wait for the meshing to complete. It can take few minutes, after mesh generation $\rightarrow$ see the partial view meshing $\rightarrow$ closer view meshing $\rightarrow$ colour element plot in case of any problem $\rightarrow$ repeat the process $\rightarrow$ see the element numbers $\rightarrow$ colours of sections $\rightarrow$ check the uniformity of it.

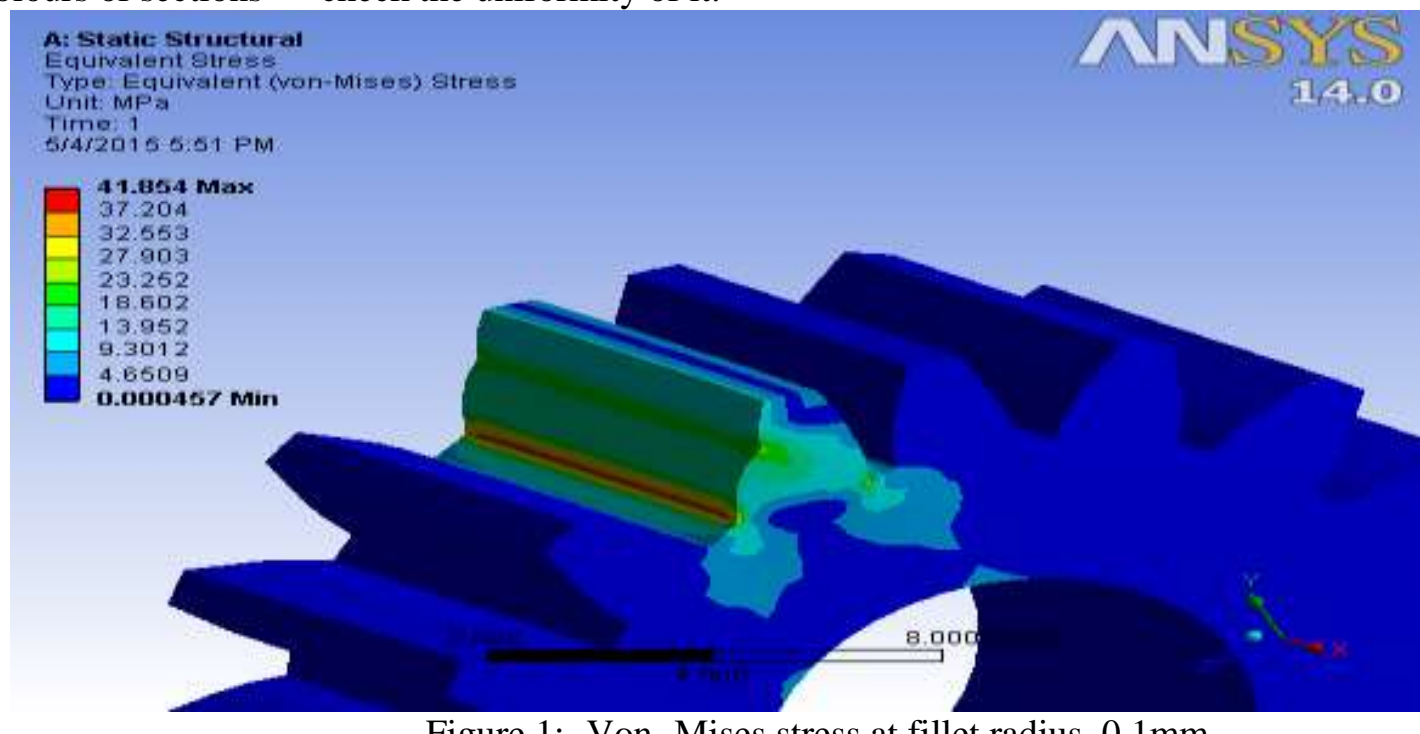

Figure 1:- Von- Mises stress at fillet radius $0.1 \mathrm{~mm}$

Step 4:- Fillet radius.

These models are modified by changing the fillet radius of values $0.1 \mathrm{~mm} \rightarrow 0.2 \mathrm{~mm}, \rightarrow 0.3 \mathrm{~mm}$ $\rightarrow 0.4 \mathrm{~mm} \rightarrow 0.5 \mathrm{~mm}$; graphical image of tooth profile for fillet radius $0.1 \mathrm{~mm}, 0.2 \mathrm{~mm}, 0.3 \mathrm{~mm}$. After this, the steps of 1 upto 3 are repeated for obtaining the mesh.After this, boundary conditions are applied by keeping the center of the gear fixed.Apply load of $150 \mathrm{~N}$, at the pitch circle diameter, of the single tooth.

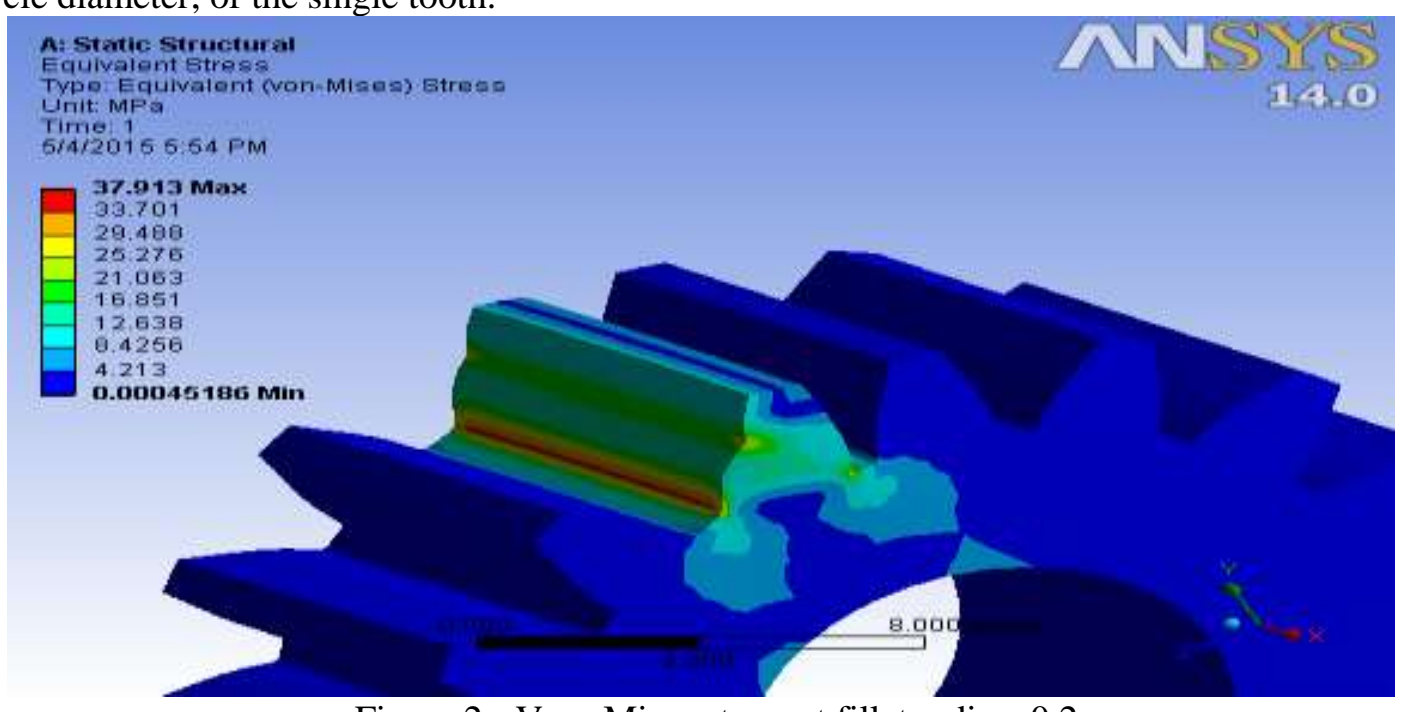

Figure 2:- Von- Mises stress at fillet radius $0.2 \mathrm{~mm}$ 


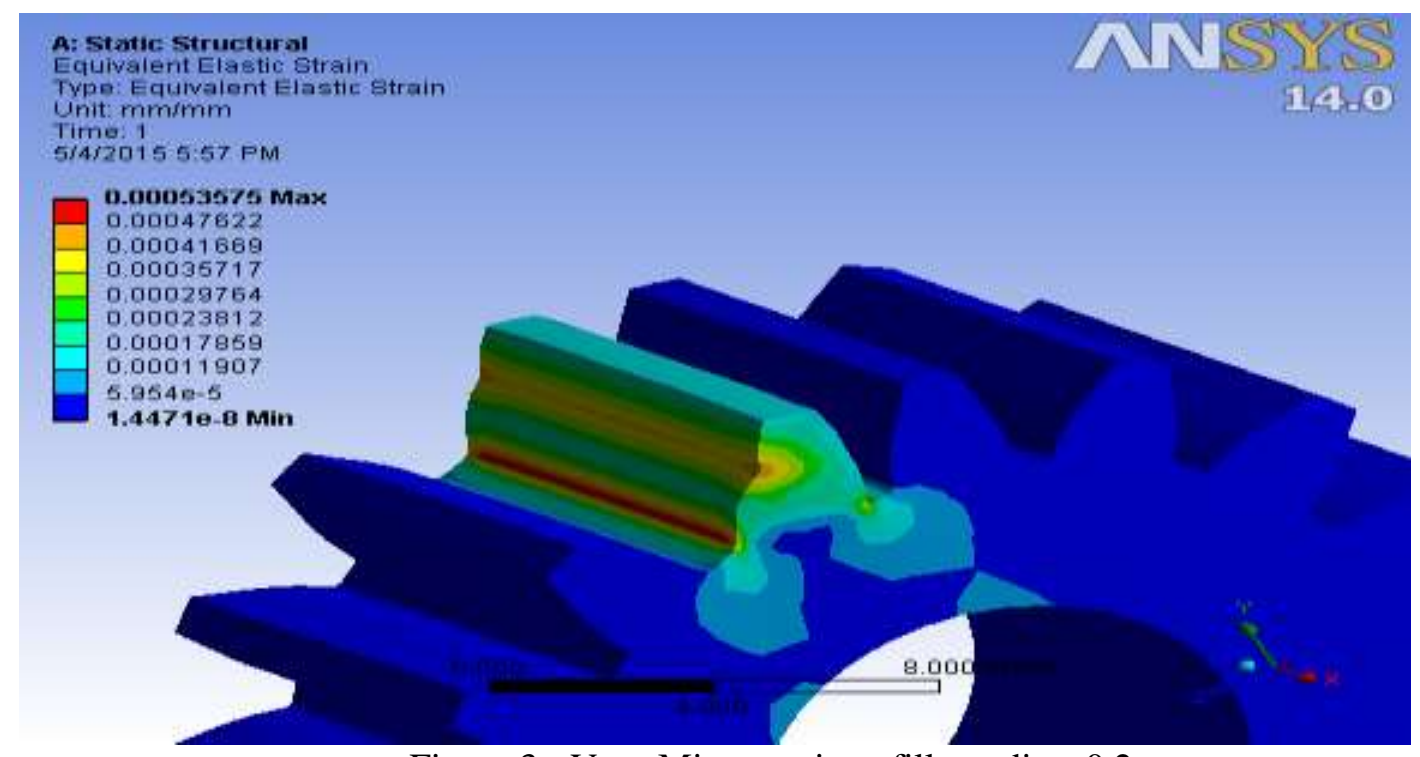

Figure 3:- Von- Mises strain at fillet radius $0.2 \mathrm{~mm}$

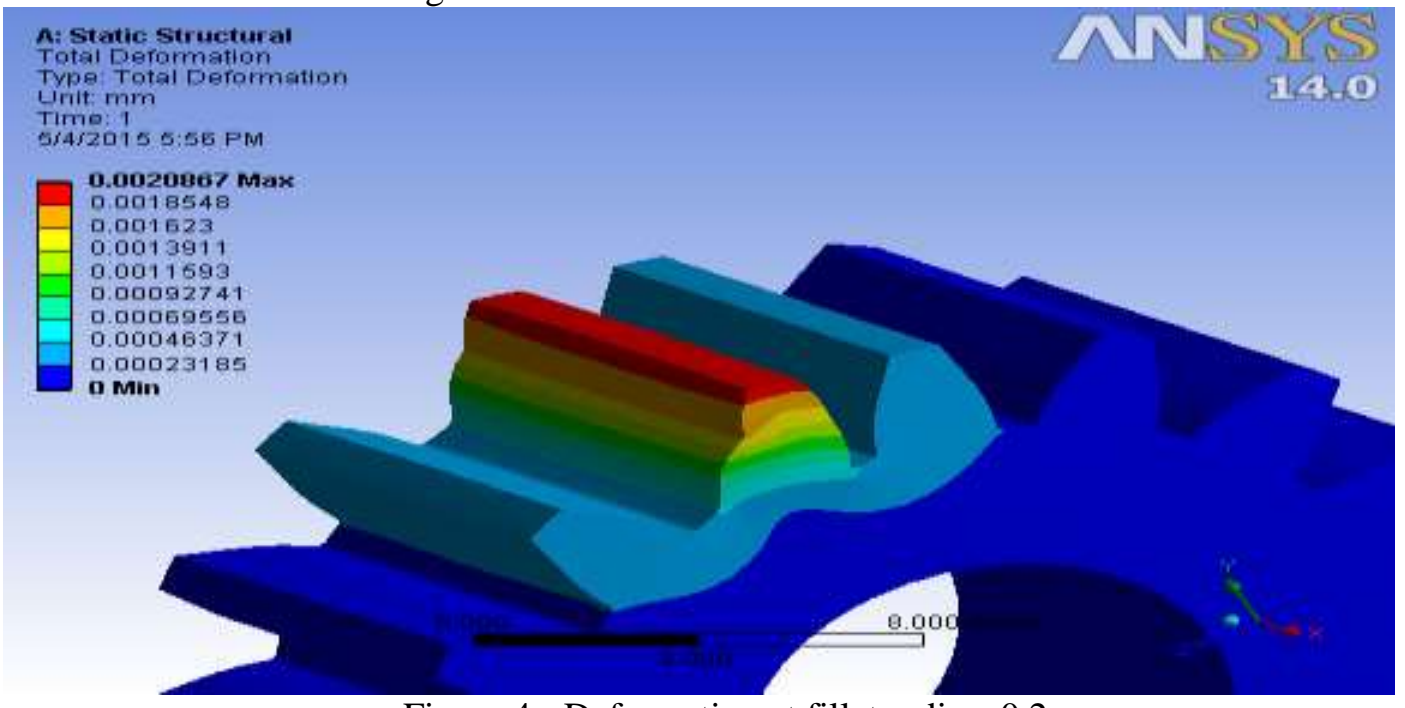

Figure 4:- Deformation at fillet radius $0.2 \mathrm{~mm}$

Factor of safety $=$ Yield stress from experimental results $/$ (Developed load stress)

\section{RESULTS}

In the post processing phase, the load of $150 \mathrm{~N}$ is applied at the pitch circle diameter. For the fillet radius of $0.1 \mathrm{~mm}$, Von-Mises stress developed is $41.85 \mathrm{MPa}$, strain is $0.00059 \mathrm{~mm}$; deflection is $0.00213 \mathrm{~mm}$. Factor of safety is 11.64 - by putting the values of Yield tensile strength from experimental results and Von Mises stress from finite element analysis, in equation number 1 . 


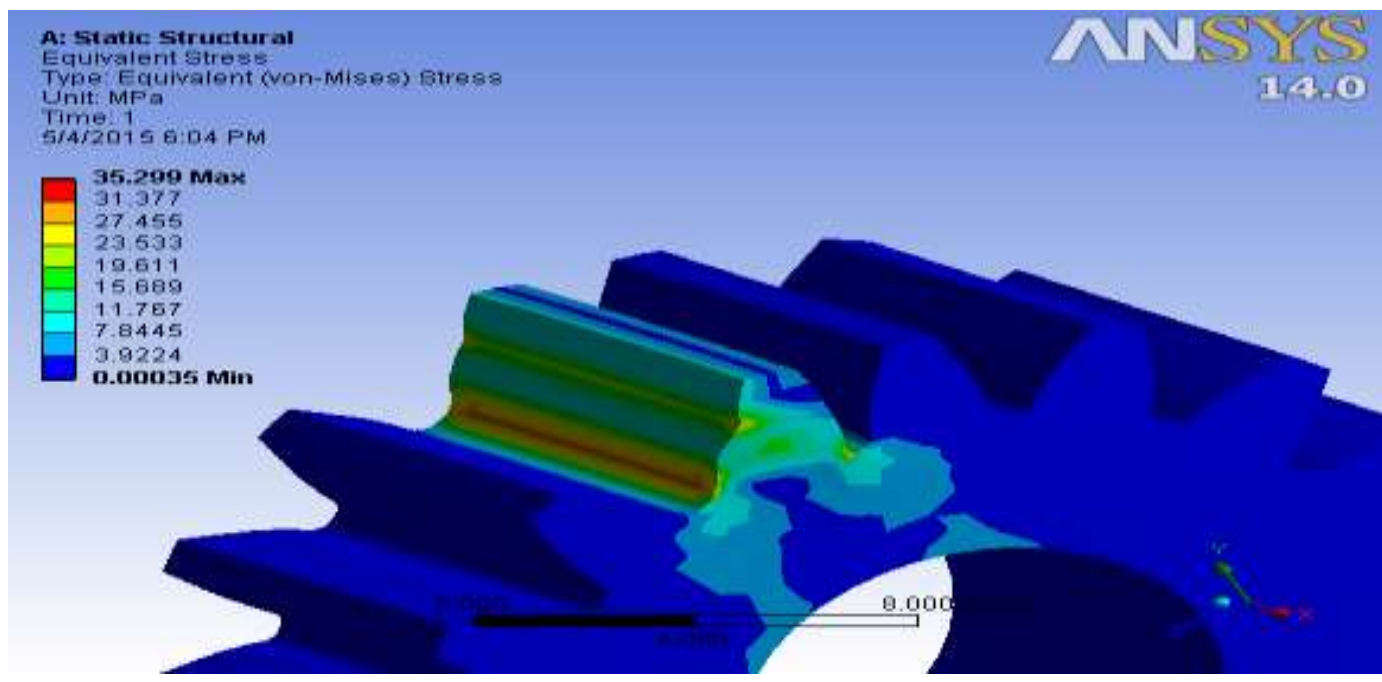

Figure 5:- Von- Mises stress at fillet radius of $0.4 \mathrm{~mm}$

The outcome from the spur gear analysis of $0.4 \mathrm{~mm}$ fillet radius: Von- Mises stress is $37.9 \mathrm{MPa}$ shown in the Figure 5; strain is $0.00053 \mathrm{~mm}$ shown in Figure 6, deformation is $0.00208 \mathrm{~mm}$ depicted in Figure 7, FOS is 12.84 from equation 1.For $0.3 \mathrm{~mm}$ fillet radius: von Mises stress is $36 \mathrm{MPa}$, strain is $0.000515 \mathrm{~mm}$, deformation is 0.00203 , FOS 13.5 from equation 1.By taking fillet radius $0.4 \mathrm{~mm}$ : von Mises stress is $35.3 \mathrm{MPa}$,strain is $0.0005 \mathrm{~mm}$, deformation is 0.00199 , FOS 14 from equation 1. When the fillet radius is $0.5 \mathrm{~mm}$ : Von- Mises stress is $27.89 \mathrm{MPa}$, strain is $0.00047 \mathrm{~mm}$, deformation is $0.00195, \mathrm{FOS}=17.46$, from equation 1 .

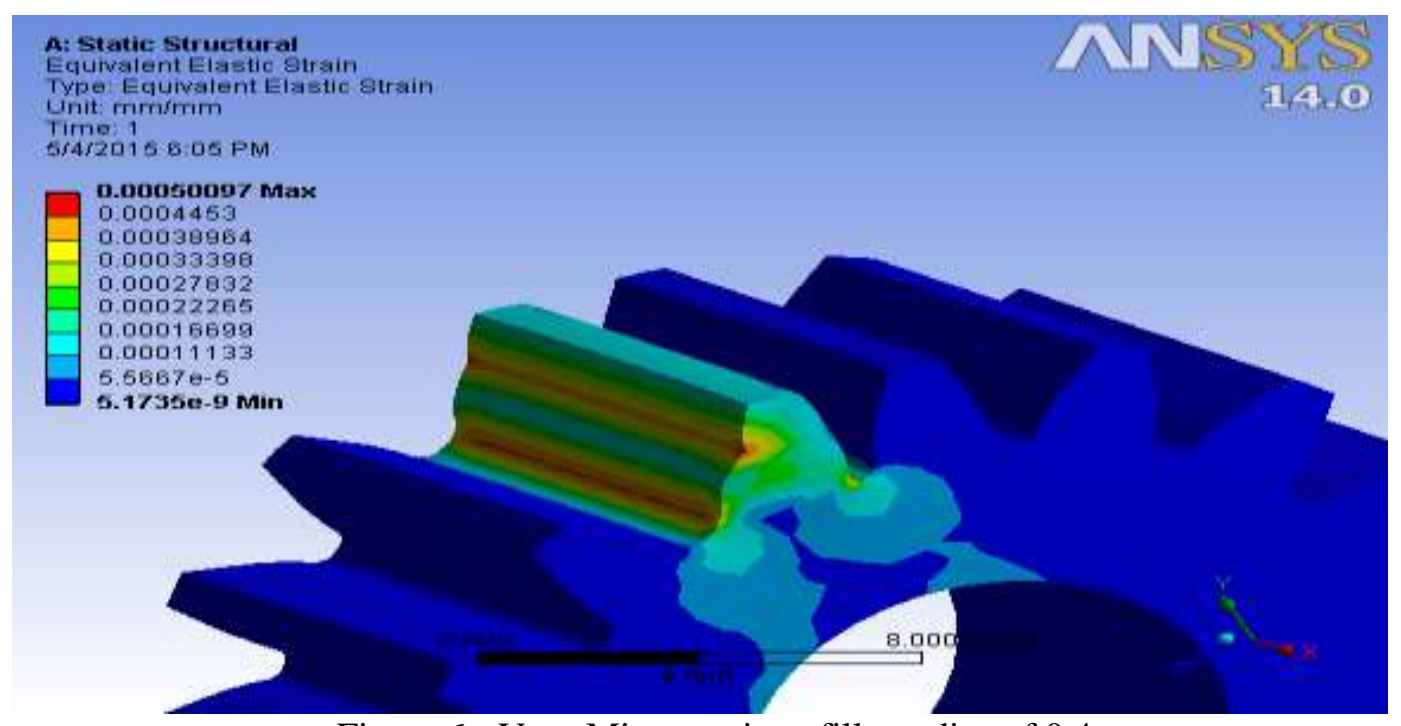

Figure 6:- Von- Mises strain at fillet radius of $0.4 \mathrm{~mm}$ 


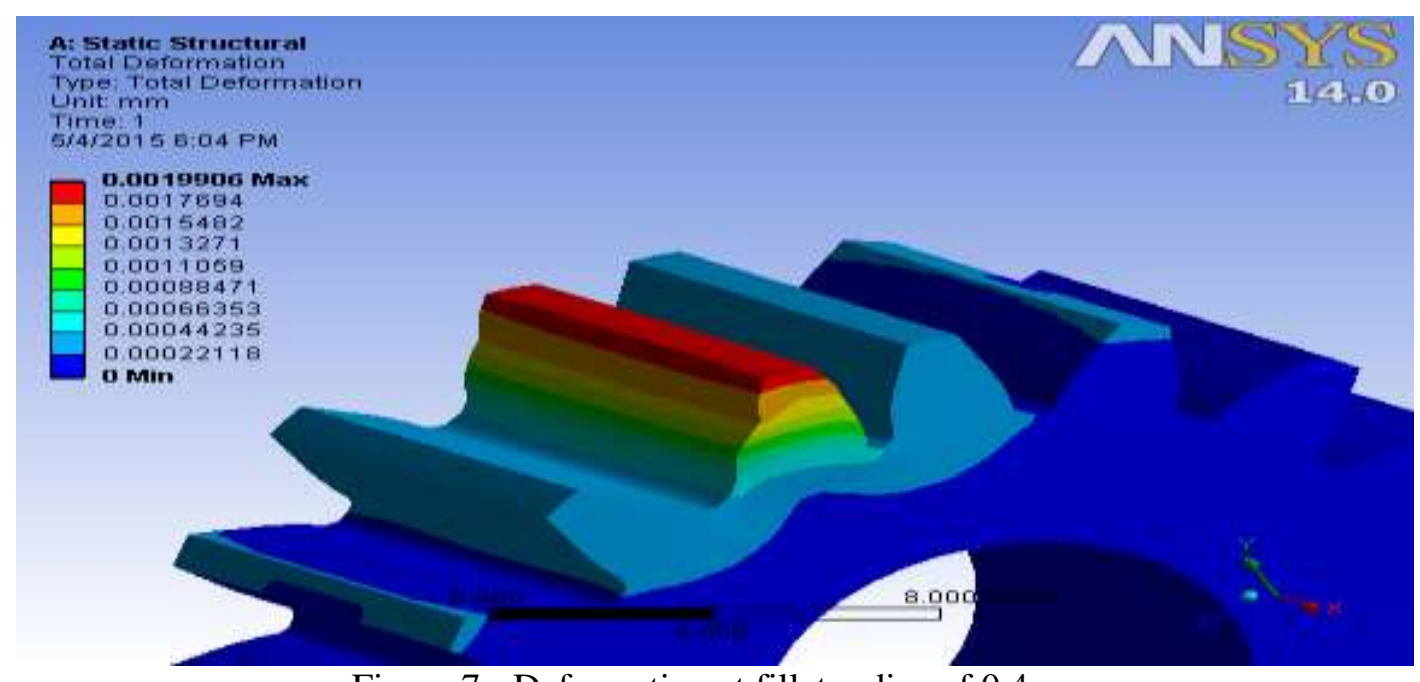

Figure 7:- Deformation at fillet radius of $0.4 \mathrm{~mm}$

The values of von Mises stress;strain;deformation \& FOS are given inTable 3, by changing the fillet radius of spur gear from $0.1 \mathrm{~mm}$ to $0.2,0.3,0.4,0.5 \mathrm{~mm}$ respectively and applying the load of $15 \mathrm{~kg}$ at the pitch circle diameter.

Table 3: Effect of fillet radius on spur gear

\begin{tabular}{|l|l|l|l|l|l|}
\hline Parameter & $\begin{array}{l}\text { Fillet } \\
0.1 \mathrm{~mm}\end{array}$ & $\begin{array}{l}\text { Fillet } \\
0.2 \mathrm{~mm}\end{array}$ & $\begin{array}{l}\text { Fillet } \\
0.3 \mathrm{~mm}\end{array}$ & Fillet 0.4mm & $\begin{array}{l}\text { Fillet } \\
0.5 \mathrm{~mm}\end{array}$ \\
\hline Load (N) & 150 & 150 & 150 & 150 & 150 \\
\hline $\begin{array}{l}\text { Von -Mises } \\
\text { stress (MPa) }\end{array}$ & 41.85 & 37.9 & 36 & 35.3 & 27.89 \\
\hline Strain(mm/mm) & 0.00059 & 0.00053 & 0.00051 & 0.0005 & 0.00047 \\
\hline $\begin{array}{l}\text { Deformation } \\
(\mathrm{mm})\end{array}$ & 0.00213 & 0.00208 & 0.00203 & 0.00199 & 0.00195 \\
\hline FOS & 11.64 & 12.84 & 13.5 & 14 & 17.46 \\
\hline
\end{tabular}

\section{DISCUSSIONS}

The increase in value of fillet radius is restrained by the fact that there should not be any interference between gears when teeth are in contact. The interference is likely not to happen when the fillet radius is too high. When the gear is cut with the standard gear shaper, the cutting tool will interfere with the portion of tooth below base circle and will cut away the interfering material. This will result in undercutting which weakens the tooth by removing material. The fillet radius increments have a positive effect on the design parameters of spur gears but it is restrained by interference and undercutting.It is evident from Table 3 and Figure 8 shows that with the increase in fillet radius, the Von- Mises stress goes on decreasing from the magnitude of $41.85 \mathrm{MPa}$ to $27.89 \mathrm{MPa}$. 


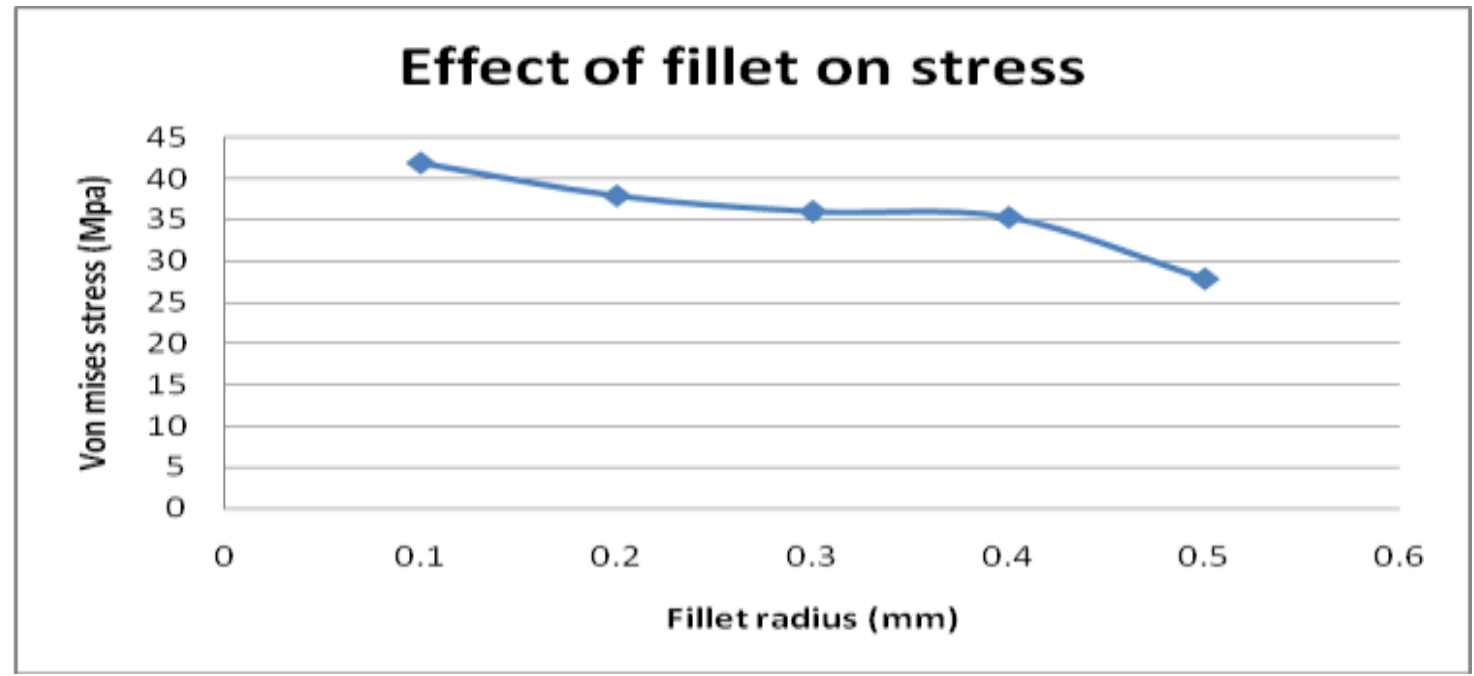

Figure 8:- Variation of Von-Mises stress with respect to fillet radius

As the fillet radius of the gear tooth changes its value from $0.1 \mathrm{~mm}$ to $0.5 \mathrm{~mm}$ the strain starts decreasing from the maximum value to minimum value of 0.00047 .Figure 9 shows the graphical representation of strain verses fillet radius.

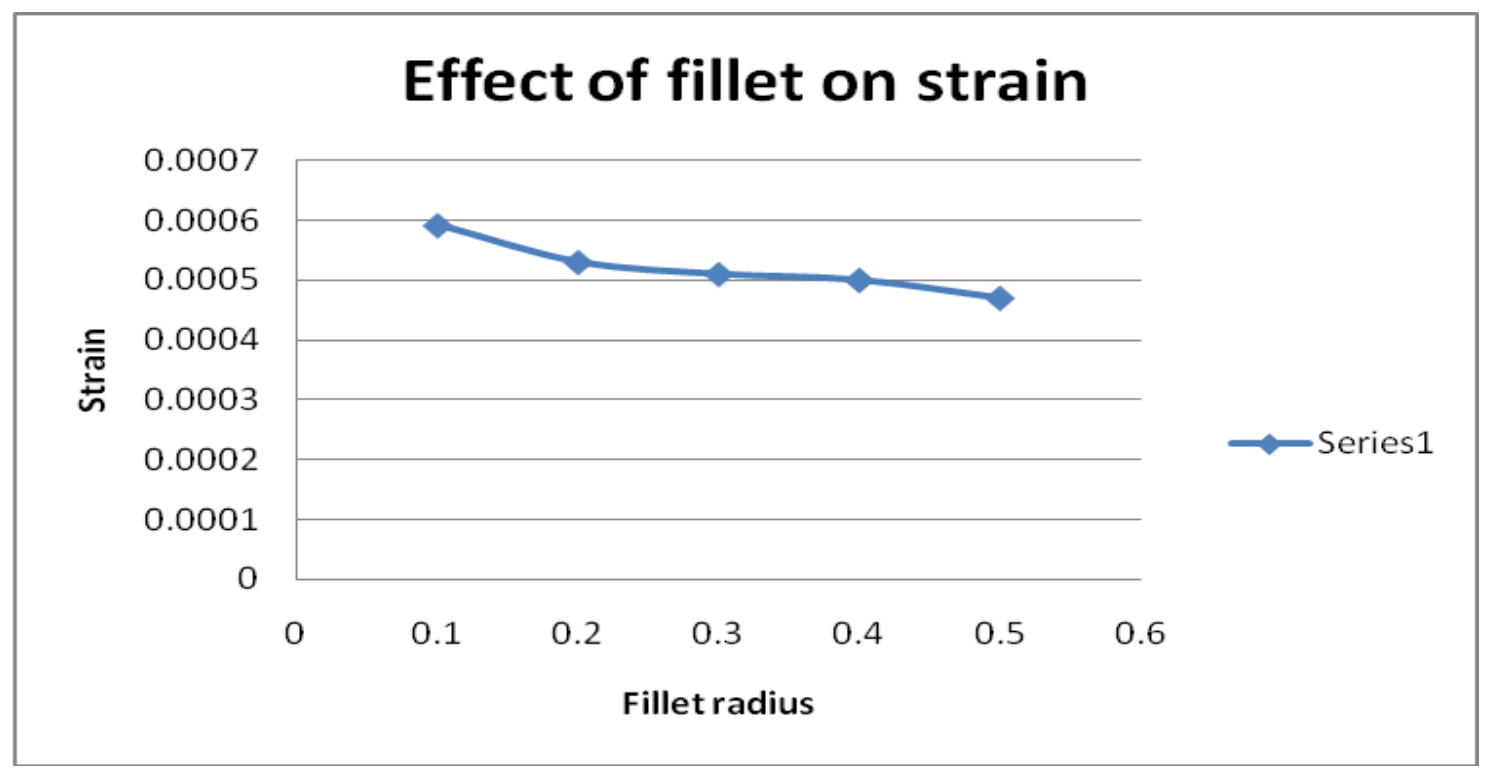

Figure 9:- Variation of Von- Mises strain with respect to fillet radius

Deformation starts decreasing with the increase of tooth fillet radius, it enhances the torque transmission, reduces the noise and vibration, because of the increase in rigidity of the tooth, which acts as a cantilever beam. Figure 10 shows the decline of deformation with respect to fillet radius. 


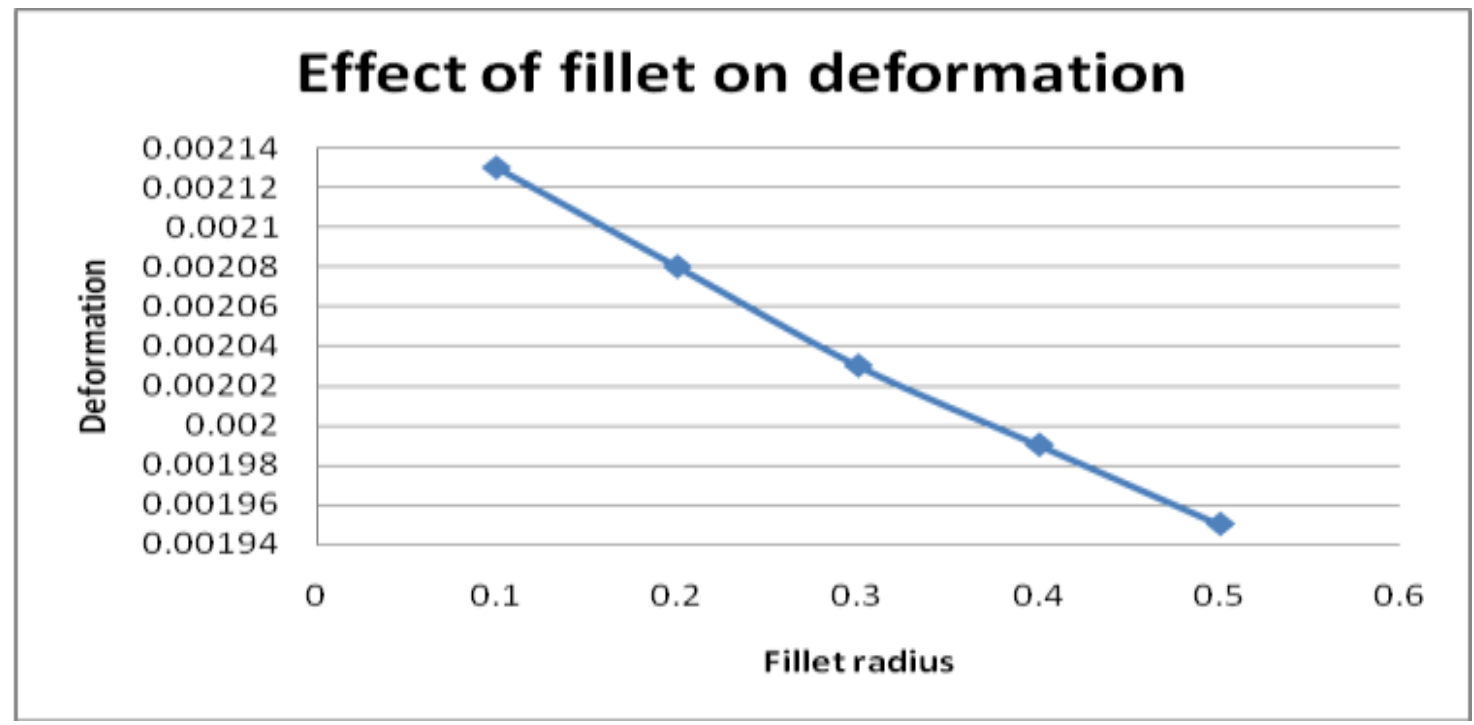

Figure 10:- Deformation of tooth with respect to fillet radius at $15 \mathrm{~kg}$ load.

Due to decrease in von Mises stress by increasing the fillet radius, the factor of safety of designed spur gear increases, results in the increase of life and load carrying capacity in other terms if we increase the load by keeping same factor of safety the gear can transmit more torque.Figure 11 shows the factor of safety versus fillet radius graph at $150 \mathrm{~N}$ load.

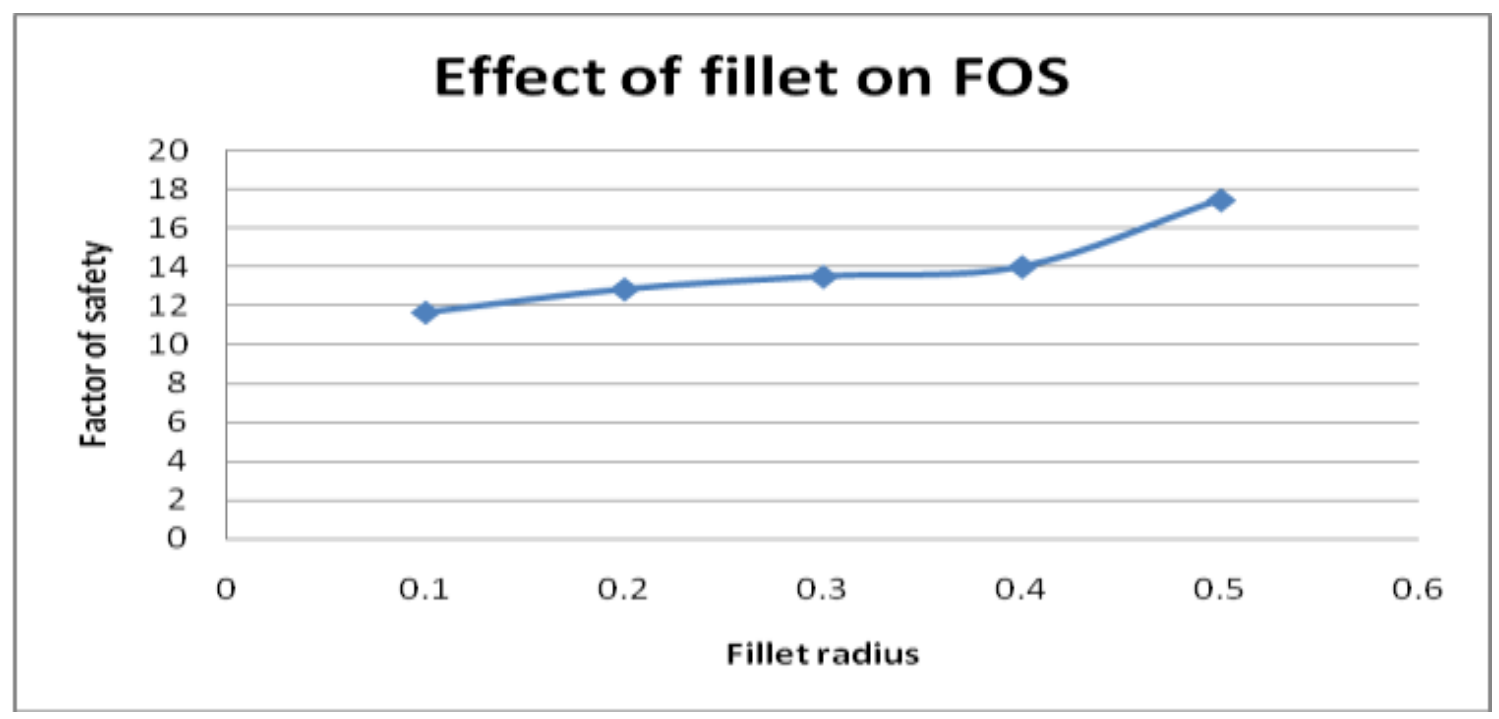

Figure 11:- Variation of factor of safety with respect to fillet radius.

\section{ConcLuSions}

The paper has accomplished the following for $\mathrm{Al}-\mathrm{SiC}$ metal matrix composite fine pitch spur gear as follows:

1. A step-by-step procedure in gear design of composite material has been developed in Ansys workbench. Designing various parameters taking into account the effect of tooth fillet radius, will reduce the stress concentration in the metal matrix composite material. 
2. An increase in tooth fillet radius reduces Von-Mises stress and strain of Al-SiC material. Higher tooth fillet radius reduces stress concentration at the gear teeth .

3. With increasing tooth fillet radius, there is increase in the factor of safety of the metal matrix composite material and hence safe design.

4. The deformation decreases with the tooth fillet radius increments. A linear relation was found between tooth fillet radius and deflection.

5. The increase in value of fillet radius is restrained by the fact that there should not be any interference.

\section{LIMITATIONS}

Limitations of the work are as follows:-

1. There may be a error of $5-10 \%$ in ANSYS results.

2. The analysis has been done for particular type of spur gear. The result may vary for other geometry and material of gear.

3. Physical model is prepared but its actual testing in vehicle will take several years.

\section{ACKNOWLEDGEMENTS}

Authors thank editorial team of International Journal of Recent advances in Mechanical Engineering for the valuable suggestions and providing such a good platform for the researchers and the readers to interact in the field of engineering.

\section{REFERENCES}

[1] A. Kapelevich \& Y. Shekhtman, (2009), "Tooth Fillet Profile Optimization for Gears with Symmetric and Asymmetric Teeth" Gear Technology, September/October,pp 73-79.

[2] Christos A. Spitas \& Vasilis A. Spitas, (2006), "Generating Interchangeable 20 degree Spur Gear Sets with Circular Fillets to Increase Load Carrying Capacity.” Gear Technology, pp. 28-34.

[3] R Prabhu sekar \& G Muthuveerappan, (2014), “ Effect of backup ratio and cutter tip radius on uniform bending strength design of spur gears" Procedia Materials Science,Vol. 5,pp1640-1649.

[4] Shanmugasundaram Sankar,Maasanamuthu Sunder Raj \& Muthusamy Nataraj, (2010), 'Profile modification for Increasing the Tooth Strength in Spur Gear Using CAD” Scientific Research,Vol. 2,pp 740-749.

[5] N.L. Pederson , (2014), 'Minimizing tooth bending stress in spur gears with simplified shapes of fillet and tool shape determination" Engineering optimization, Taylor \& Francis,pp1-19.

[6] Ognyan Alipiev, Sergey Antonov \& Tanya Grozeva (2013), "Generalized model of undercutting of involute spur gears generated by rack cutters" Mechanism and Machine Theory, Vol. 64,pp 39-52.

[7] Th. Costopoulos \& V. Spitas, (2009), "Reduction of gear fillet stresses by using one sided invloute asymmetric teeth" Mechanism and Machine Theory,Vol 44,pp1524-1534.

[8] Ashwin Joshi \& Vijay Kumar Karma, (2011), "Effect on strength of Involute Spur Gear by Changing the Fillet Radius Using FEA” International Journal Of Scientific \& Engineering Research , Vol. 2, Issue 9, pp 1-5.

[9] J.L. Woods, S.R. Daniewicz \& R. Nellums (1999), "Increasing the bending fatigue strength of carburized spur gear teeth by presetting” International Journal of Fatigue, Vol. 21,pp 549-556. 
[10] Mir Ali Ghaffari, Eic Pahl \& Shaoping Xiao (2015), "Three dimensional fatigue crack initiation and propagation analysis of a gear tooth under various load conditions and fatigue life extension with boron / epoxy patches" Engineering Fracture Mechanics, Vol. 135, pp 126-146.

[11] Tengjiao Lin, H. Ou \& Runfang Li (2007), "A finite method for 3D static and dynamic contact/impact analysis of gear drives" Computers methods in applied mechanics and engineering, Vol. 196, pp 1716-1728

[12] Harold van melick (2007) "Tooth Bending Effects in Plastic Spur Gear" Gear Technology, September / October, pp 58-66.

[13] Nizar Ahmed, Yogesh Pandya \& Anand Parey (2014), "Spur gear tooth root crack detection using time synchronous averaging under fluctuating speed" Measurement, Vol. 52, pp1-11.

[14] Yogesh Pandya \& Anand Parey (2013) "Simulation of crack propagation in spur gear tooth for different gear parameter and its influence on mesh stiffness" Engineering Failure Analysis, Vol. 30, 124-137.

[15] Bernd Robert Hohn, Peter Oster \& Christo Brayoff (2011) "Size and Material Influence on the Tooth Root, Pitting, Scuffing and Wear Load Carrying capacity of Fine Module Gears" Gear Technology, September / October,pp 34-40.

[16] S. Senthilvelon \& R. Gnanamoorthy (2005) "Effect of gear tooth fillet radius on the performance of injection moulded Nylon 6/6 gears" Materials \& Design, Vol. 27, pp 632-639

[17] V. Senthil Kumar, D.V. Muni \& G. Muthuveerappan (2007) "Optimization of asymmetric spur gear drives to improve the bending load capacity" Mechanism and machine theory, Vol. 43, pp 829-858.

[18] Jose I. Pedrero, Miguel Pleguezuelos, Marta Munoz (2011), "Contact stress calculation of undercut spur and helical gear teeth" Mechanism and Machine Theory, Vol. 46, pp1633-1646.

[19] Machine Design - An Integrated Approach by R.L. Norton, Second ed., Pearson Education.

\section{Authors}

Atul Sharma is PhD student in the Department of Mechanical Engineering, YMCA University of Science and Technology, Faridabad, Haryana, India. Presently he is working as Senior Instructor in machine shop. He is currently doing research on spur gear materials. He had published many research papers in journals and attended International and National conferences. His area of interest is Manufacturing and Design.

Dr. M.L. Aggarwal has done B.Sc. (Mechanical Engg.) from REC Kurukshetra,Haryana, India in 1988, M.Tech. and PhD. from IIT New Delhi in 2003 and JMI New Delhi in 2007 respectively. He has been working in YMCA University of Science \& Technology Faridabad, Haryana,India since 1989. He has published 50 papers in International / National Journals in the relevant areas of design engineering. His research areas of interest are materials and design

Dr. Lakhwinder Singh is working as a Associate Professor in YMCA University of Science \& Technology Faridabad, Haryana, India. He had guided many students project at masters and bachelor level. He had published many research papers in various reputed journals and attending many International and National conferences. His research area is Shot peening and materials.
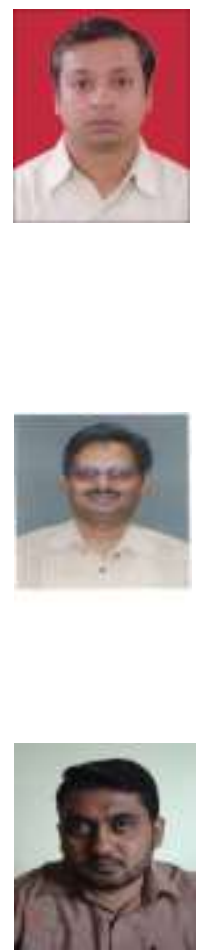